\title{
NO HORIZONTE EU VEJO A ÁGUA: UMA ANÁLISE DE TRES AGUAS, UM PROJETO DE ARTE PÚBLICA EM/PARA TOLEDO
}

\section{ON THE HORIZON I SEE WATER: AN ANALYSIS OF THREE WATERS, A PROJECT OF PUBLIC ART IN/FOR TOLEDO}

MARYELLA SOBRINHO 


\section{Resumo}

No presente texto propomos uma análise do projeto Tres Aguas, um projeto de intervenção urbana realizado pela artista espanhola Cristina Iglesias. A reflexão toca três aspectos: a relação entre passado e presente, a cidade como lugar de partilha do sensivel e a arte em espaço público. Para fundamentar nossa abordagem, nos apoiamos em Jacques Rancière, com Políticas da escrita (1995) e A partilha do Sensivel (2005).

Palavras-chave: Intervenção urbana. Partilha do sensível. Toledo. Cristina Iglesias.

\section{Abstract}

We propose an analysis of the Tres Aguas project, starting from the presentation of a series of events. The reflection addresses three aspects: the relationship between past and present, the city as a place of distribution of the sensible and art in public space. To support our approach, we rely on Jacques Rancière.

Keywords: Urban intervention. Distribution of the sensible. Toledo. Cristina Iglesias.

ISSN: 2175-2346 


\section{Introdução}

A discussão que se segue pretende abordar a relação entre o conjunto escultórico Tres Aguas com o espaço urbano de Toledo, considerando também sua historicidade. A abordagem que desenvolvemos inicia-se com uma breve descrição da obra, que faz parte de uma série de trabalhos denominados Zonas Freáticas ${ }^{1}$, devido a incorporação da água como elemento constitutivo. Os componentes estão distribuídos em diferentes espaços da cidade, e por este motivo, narramos também o percurso efetuado para observar e documentar Tres Aguas em sua totalidade. Ao longo do texto, trazemos à tona eventos do passado medieval da cidade para verificar de que maneira eles se relacionam com a atualidade e questões relacionadas à arte em espaço público, considerando que o espaço urbano é lugar de partilha do sensível, conceito proposto por Jacques Rancière (2005).

\section{Tres Aguas, um projeto para Toledo}

Em 2014, a artista espanhola Cristina Iglesias (San Sebastian, 1956-) inaugurou a obra Tres Aguas em Toledo (Espanha). Trata-se de um conjunto escultórico formado por três intervenções em espaços históricos da cidade: a Torre del Agua, a Plaza del Ayuntamiento e o Convento de Santa Clara. Tais intervenções são abscessos feitos no chão, semelhantes a piscinas, cujo fundo é um relevo esculpido que imita uma massa vegetal de folhas e galhos. No seu interior, a água percorre toda a sua extensão em um intervalo de tempo pré-determinado pela artista e executado por um sistema mecânico interno. Temos a possibilidade de caminhar ao seu redor e observar o fluir das águas por toda a superfície esculpida. Essas intervenções são um desdobramento de uma série de trabalhos denominada Zonas Freáticas, desenvolvida desde 2000. Tal série abrange também poços que contêm água e relevos que imitam formas orgânicas. Em todas as peças do conjunto, devemos ter a precaução de não nos deixar enganar pela semelhança que possuem com o fundo de rios e lagos.

Como parte do projeto, Iglesias produziu um vídeo ${ }^{2}$ que apresenta cada uma das intervenções e imagens de Toledo, capturadas a partir de um percurso pelo espaço urbano. No intervalo de quase 15 minutos, Almudena Cencerrado, Presidente da Associação Nacional de Guias de Turismo apresenta a cidade, e acompanhando uma visitante por vários espaços urbanos, traz à tona uma sequência de fragmentos de sua história. O percurso recomendado no vídeo, inicia-se na Torre del Agua, sugestão que seguiremos para iniciar nossa abordagem.

A Torre del Agua está situada fora dos limites da cidade histórica, cercada pelas muralhas medievais. (Fig. 1) O edifício localiza-se dentro do campus da Universidad de Castilla La Mancha, uma antiga fábrica de armas. Construído em estilo mourisco, passou anos abandonado e fechado após perder sua função principal: armazenar água canalizada do rio que contorna a cidade, o Tejo. Ao entrar no edifício, visualizamos um abismo cuja forma é pouco discernível à distância. Somente quando nos

$1 \quad$ Ver http://cristinaiglesias.com/. Acesso em: 19 mar. 2018.

2 Disponível em https://www.youtube.com/watch?v=qbHcdTOny_U. Acesso em: 10 mar. 2018. 
aproximamos, constatamos que o fundo desta cavidade está tomado por um emaranhado de formas vegetais. Aos poucos, a cavidade é coberta por água, até ficar completamente submersa. E então a água volta a escorrer por canais escondidos. O vão torna a esvaziar-se e o fundo é revelado novamente. Para acessar o topo da torre é preciso subir uma escada interna. À medida que subimos três andares, passamos por janelas fechadas por uma película cuja aparência se assemelha às nuvens. Finalmente, quando alcançamos o topo da construção, podemos apreciar o Tejo e o panorama das muralhas medievais de Toledo. Após a Torre del Agua, partimos para o casco histórico ${ }^{3}$ da cidade.

Deixando o campus da universidade, contornamos as muralhas até alcançar uma de suas portas, a Puerta de Alfonso VI. Se seguirmos caminhando por suas ruas labirínticas, atravessamos a Judería, bairro formado pelas primeiras comunidades sefarditas ${ }^{4}$. Passamos por uma série de edifícios religiosos (Sinagoga Santa Maria la Blanca, Catedral Primária, Mesquita) até chegar à Plaza del Ayuntamiento, onde se encontra outra intervenção de Iglesias. (Fig. 2) Ao redor da praça estão a Catedral de Toledo, o Palácio Arzobispal, o prédio do Ayuntamiento de Toledo e o Palacio de Justicia, além das frequentes feiras que ocorrem nos fins de semana e feriados. Toda esta estrutura tem sua imagem refletida no espelho d'água que ocupa a região central. $A$ rasa piscina feita por Iglesias tem o formato de um retângulo assimétrico, seguindo a irregularidade da própria praça. Embora não tenha a mesma profundidade daquela presente na Torre del Agua, possui o relevo semelhante. O emaranhado de raízes artificiais, que parece estar em decomposição, é cortado por uma fenda longitudinal que permite o fluxo de água. Estando em um local público e aberto, não é difícil encontrar folhas naturais que se camuflam na natureza artificial; ou aves que bebem daquela água, talvez enganadas pela simulação de um pequeno lago. Esta praça é um dos lugares mais agitados de Toledo; por ali transitam moradores e turistas todos os dias da semana.

3 Conjunto de construções que se desenvolve em um espaço geográfico determinado. É "histórico" por ser estar vinculado a feitos passados, cuja relevância exige estudo. Definição disponível em https://definicion.de/casco-historicol. Acesso em: 28 jun. 2018.

4 Descendentes de judeus originários de Portugal e Espanha (MONZÓN, MATILLA, 2013, p. 10). 


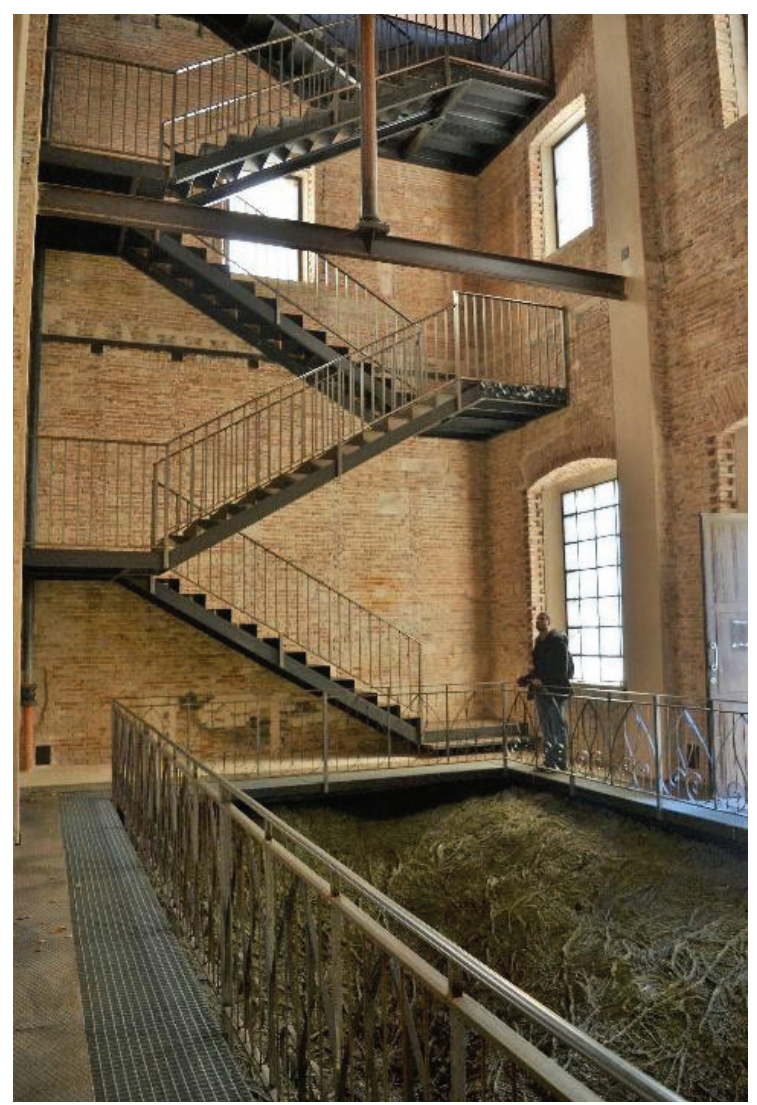

Fig. 1 - Tres Aguas, Cristina Iglesias, 2014. Escultura, dimensões variáveis. Torre del Agua. Toledo, Espanha.

Fonte: Arquivo Pessoal

Em contraponto, a última obra está localizada entre as paredes silenciosas do Convento de Santa Clara. (Fig. 3) Após passar pela Bab-al-Mardum, chegamos à parte mais alta de Toledo. Por este motivo, é também onde estão várias cisternas e poços que captam a água pluvial a ser utilizada na irrigação de jardins espalhados pela cidade. Após subir um pequeno lance de escadas, temos acesso à última zona freática, encerrada num ambiente fechado e separada do resto do convento por uma mashrabiya ${ }^{6}$, espécie de treliça em ferro. A mesma estrutura se repete no interior da sala, protegendo da iluminação direta o abscesso feito no chão. De maneira diversa da intervenção anterior, na Plaza del Ayuntamiento, este é um espaço solitário; seja pelo peso da instituição religiosa, seja pelo silêncio do local fechado. Ali, podemos nos sentar no banco existente e observar o fluxo de água que vela e desvela a massa vegetal. Podemos meditar na penumbra promovida pela mashrabiya ou apenas caminhar ao redor da obra.

Todo o trajeto que somos levados a percorrer para observar Tres Aguas nos transporta para um passado medieval, período de formação urbana e cultural de To-

5 Uma das portas medievais de Toledo, antes com função defensiva.

6 Também pode ser feita em madeira. Ao ser colocada em janelas e aberturas semelhantes, permite que as pessoas que estão no interior de uma habitação visualizem o exterior com discrição. São elementos decorativos que, além de garantir privacidade, permitem a passagem de ar e luz. Sua função e aparência remetem à arte hispano-muçulmana, que se forma na Península Ibérica entre os séculos 8 e 10. Esta treliça também faz parte do repertório de obras de Cristina Iglesias, na série Celosias (MÍGUEZ, 2008). 
ledo. Os edifícios citados são emblemáticos na cidade: cada um deles foi local de culto das três principais religiões dominantes na Espanha da Idade Média: o cristianismo, o islã e o judaísmo. Os lugares eleitos para receber cada uma das intervenções não são aleatórios. Para ir de um espaço a outro, é preciso se perder pelas ruas sinuosas, atravessar jardins e observar a paisagem urbana.

\section{O que teria pensado a artista ao desenvolver este projeto? A princípio,}

(...) Ao fazer Tres Aguas (...) Cristina Iglesias extraiu da história cultural da cidade sua mistura e camadas de comunidades muçulmanas, judaicas e cristãs que viveram lado a lado durante séculos, no período conhecido como "La Convivencia" ou "A Coexistência". As três obras escultóricas que compõem o projeto evidenciam a água; que percorre canais e viaja de volta ao chão depois de animar as superfícies das obras, para que elas se assemelhem ao leito de algum antigo rio. Os visitantes são levados em uma viagem pela cidade enquanto visitam cada obra, de uma torre de água mudéjar para o principal espaço público da cidade e, em seguida, para um local escondido dentro de um convento, um lugar normalmente não aberto aos visitantes. Concebido como uma viagem ao coração da cidade, o projeto de Iglesias alinha os materiais duros da arquitetura e a fluidez da água para entregar uma sequência de grandes obras escultóricas que trazem o rio de volta para o corpo desta cidade histórica. (TRES, 2014, Tradução nossa). ${ }^{7}$

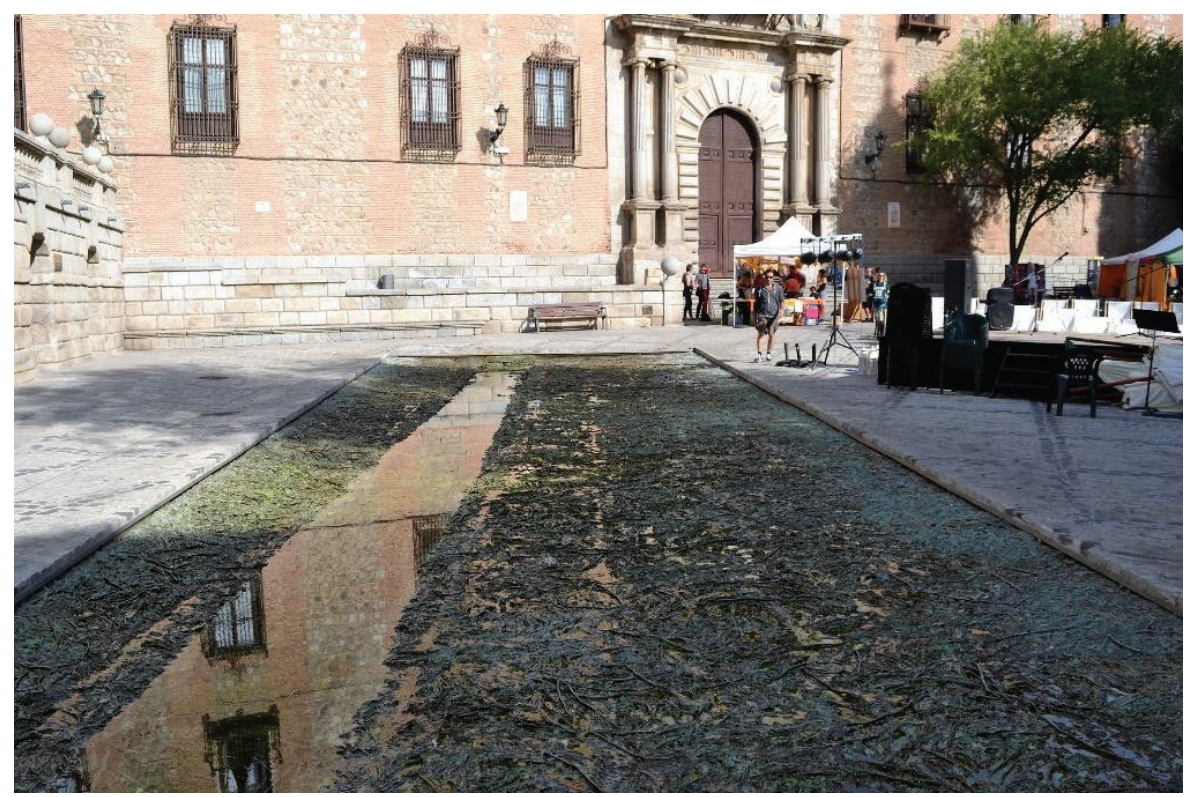

Fig. 2 - Tres Aguas, Cristina Iglesias, 2014. Escultura, dimensões variáveis. Plaza del Ayuntamiento.

Toledo, Espanha. Fonte: Arquivo Pessoal

\footnotetext{
7 "(...) In making Tres Aguas (...) Cristina Iglesias drew from the cultural history of the city, its mingling and layering of Muslim, Jewish and Christian communities who lived alongside each other for centuries in the period known as "La Convivencia" or The Co-existence. The three sculptural works that make up the project bring water to the fore; it courses through channels and travels back into the ground after animating the surfaces of the works so they come to resemble the overgrown bed of some ancient river. Visitors are taken on a journey through the city as they visit each work, from a mudéjar water tower to the city's main public space and then onto a hidden location within a convent, a place not normally open for visitors. Conceived as a journey into the heart of the city, lglesias' project aligns the hard materials of architecture and the fluidity of water to deliver a sequence of large-scale sculptural works that bring the river back into the body of this historic city." (TRES, 2014) Disponivel em http://www.cristinaiglesias.com/exposiciones/Tres-Aguas-A-Project-for-Toledo-2014/. Acesso em: 20 mar. 2017.
} 


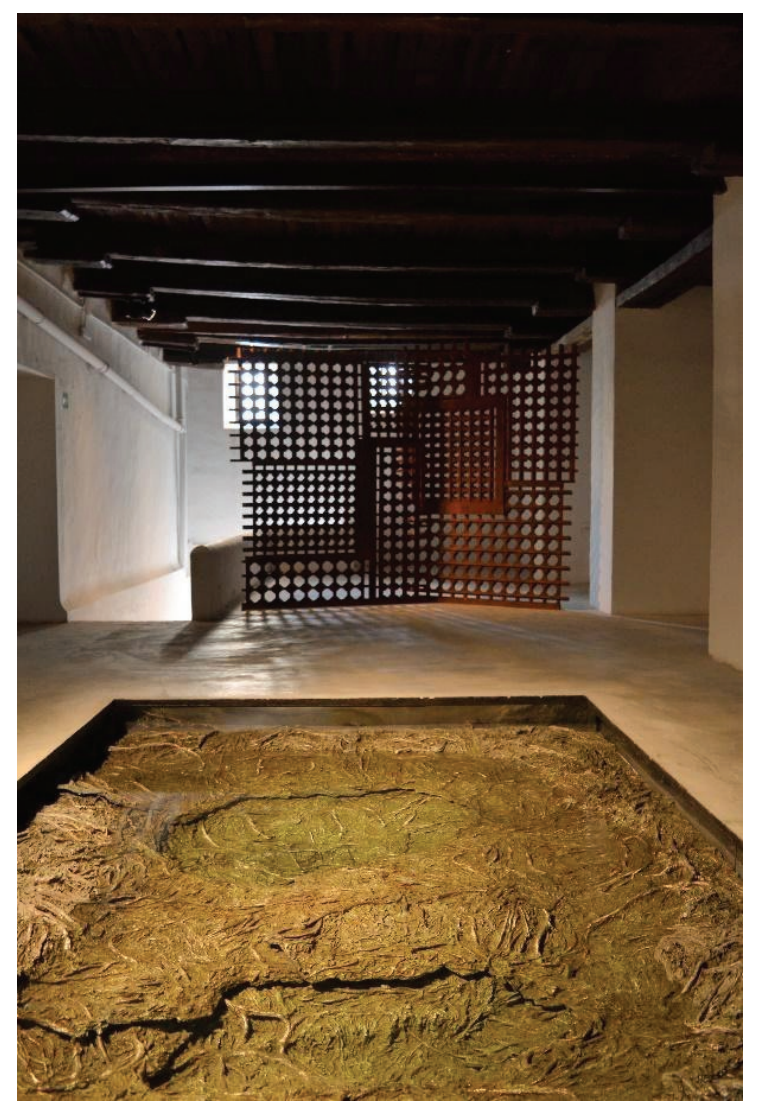

Fig. 3 - Tres Aguas, Cristina Iglesias , 2014. Escultura, dimensões variáveis. Convento de Santa Clara.

Toledo, Espanha. Fonte: Arquivo Pessoal

De fato, a história de Toledo é marcada pela presença das três culturas na Idade Média. Vejamos como ocorreu sua formação histórica e como ela se relaciona com o conjunto escultórico de Tres Aguas.

\section{Toledo e o espaço partilhado}

"Se existe alguma cidade no mundo que reflete de forma exemplar a confluência das três principais culturas do Mediterrâneo, esta é, sem dúvida, Toledo."8 Assim começam Olga Monzón e Enrique Picavea (2013, p.4) sua análise do cenário da Toledo medieval. A presença das "três culturas" em Toledo inicia-se no século 8 . No intervalo de 800 anos, a cidade passou por diferentes etapas de controle político. A primeira delas refere-se ao domínio muçulmano, entre os anos 711 e 1085 . As tropas do general Tárique cruzaram o estreito de Gibraltar e chegaram às margens do rio Tejo, região pouco habitada por cristãos. Encontraram muitos judeus que permaneceram e que, ao colaborar com os muçulmanos, foram beneficiados. Ali os muçulmanos iniciaram a formação de Al-Andaluz, território que abrangia parte de Portugal e grande parte da Espanha.

$8 \quad$ "Si existe alguna ciudad en el mundo que refleje de manera ejemplar la confluência de las tres culturas principales del Mediterraneo ésta es sin duda Toledo." Tradução nossa (MONZÓN e MATILLA, 2013, p. 4). 
O período do domínio muçulmano não foi totalmente pacífico. Desde o início, revoltas contra o poder central sediado em Córdoba eram frequentes, sempre promovidas pela população hispano-romana, muladíes ${ }^{9}$ ou moçárabes ${ }^{10}$. Finalmente submetida ao poder central de Al-Andaluz, Toledo vira centro intelectual e, em seguida, político. Em 1031, uma crise desencadeia uma fragmentação do Califado de Córdoba, que passa a ser dividido em taifas (reinos), e Toledo se torna capital da maior taifa. Entre 1043 e 1075, a cidade foi governada pela dinastia berbere ${ }^{11}$, época do reinado de Al-Mamun.

Ainda que Al-Mamun estivesse bem estabelecido como líder, em 1075 perde o poder para Al-Qadir, que governa a cidade sem aprovação da população, desencadeando nova crise e uma divisão dos muçulmanos toledanos. Parte pediu apoio a Alfonso VI (rei de Castela e Leão). A outra, apoio aos outros muçulmanos. Estes últimos foram beneficiados inicialmente. Expulsaram Al-Qadir e colocaram no poder o rei de Badajoz que, por fim, deixou Toledo para voltar a seu reino. Al-Qadir voltou ao poder, mas enfrentou nova crise e, em 1085, entregou Toledo a Alfonso VI em troca de Valência. Inicia-se, então, o período de domínio cristão.

Ao assumir o poder, o governo cristão impõe algumas condições aos muçulmanos. Estes podiam permanecer livremente na cidade, devendo pagar um imposto para Alfonso VI. Aqueles que quisessem ir embora com seus pertences tinham permissão para fazê-lo (podendo inclusive retornar a Toledo). Outra parte dos acordos refere-se ao uso dos espaços: a mesquita maior continuava como local de culto muçulmano, enquanto o Alcazar e o tesouro de Al-Qadir ficariam para Alfonso VI. A entrada do rei teve uma repercussão psicológica para todo o povo. Representava uma grande perda para os muçulmanos, pois era a primeira vez que uma cidade previamente muçulmana passava ao domínio cristão. Sentimento oposto foi gerado nos cristãos: tratava-se de um triunfo, pois, além de recuperar um antigo reino visigodo, finalmente conquistava-se um território muçulmano. Um ano e meio depois, o pacto foi descumprido: a mesquita foi convertida em catedral cristã; apesar de diferentes versões que tentam explicar o ocorrido, é certo que a imposição de um novo poder dominante desencadeou uma inicial intolerância de cultos e religiões.

Nos séculos seguintes, 13 e 14, Toledo alternou momentos de esplendor e instabilidade: a peste negra e guerras civis prejudicaram a cidade, que resistiu graças às suas muralhas e à defesa natural proporcionada pelo rio. Em meio aos conflitos entre muçulmanos e cristãos, estavam os judeus. Já ocupavam a região antes mesmo da conquista muçulmana, sendo sobreviventes das perseguições visigodas, e ali permaneceram graças à tolerância religiosa praticada pelos muçulmanos. Na verdade, os judeus viam os muçulmanos como aliados, pois, graças a eles, a monarquia visigoda havia chegado ao fim. $O$ apoio aos conquistadores permitiu a liberdade de culto nas sinagogas, escolas próprias, conservação de parte de seus bens e permissão para

\footnotetext{
9 População anteriormente cristã, que se converteu ao islã. Chamados de muladíes ou "renegados". Eram em maior número e pertenciam a uma classe social mais baixa. Eram em sua maioria camponeses e aos poucos aumentavam em número (MONZÓN e MATILLA, 2013).

10 População cristã que dominava a língua árabe e que, pela convivência, incorporou a cultura e os costumes islâmicos. Literalmente, mozárabe significa "arabizado" (MONZÓN e MATILLA, 2013).

11 Conjunto de populações do Magrebe (noroeste da África), maior em número que os árabes e que detinha grande poder militar (MONZÓN e MATILLA, 2013).
} 
exercer alguns cargos políticos, diferentemente dos moçárabes. Tinham uma atuação intermediária entre a Espanha cristã e muçulmana, devido à prática do comércio e à cobrança de impostos.

Durante uma história de 800 anos (aqui extremamente resumida), o controle político de fato esteve em mãos muçulmanas ou cristãs. Os judeus tiveram papel importante, mas sempre estiveram à margem quando se tratava de assumir o poder central. As diversas disputas pelo poder acabaram no século 15, quando os Reis Católicos expulsaram os judeus, e em 1609, quando foram expulsos os muçulmanos. Mas antes da expulsão e do predomínio cristão, como podemos pensar o período da convivência na cidade de Toledo?

A cidade é onde as relações políticas, culturais e sociais do homem se constituem. É o espaço praticado ${ }^{12}$ pelo homem, onde as formas de vida comum são produzidas, recebidas e significadas. Se tomarmos o pensamento de Jacques Rancière como meio de compreensão do chamado "período de convivência", constatamos que existe, neste espaço partilhado, uma tensão entre o que é acessível e inacessível, público e privado. A noção de partilha é esclarecida pelo autor estando associada à estética:

Pelo termo de constituição estética deve-se entender aqui a partilha do sensível que dá forma à comunidade. Partilha significa duas coisas: a participação em conjunto comum e, inversamente, a separação, a distribuição em quinhões. Uma partilha do sensivel é, portanto, o modo como se determina no sensivel a relação entre um conjunto comum partilhado e a divisão de partes exclusivas (RANCIĖRE, 1995, p. 7).

Rancière prossegue: "A partilha do sensível faz ver quem pode tomar parte no comum em função daquilo que faz do tempo e do espaço em que essa atividade se exerce" (RANCIĖRE, 2005. p. 16). A repartição é desigual: nem todos podem acessar este espaço, embora partilhado. Para o autor há uma lógica que determina o arranjo dos corpos no espaço; no caso da Toledo medieval, a lógica era definida pela religião e pela política. Pertencer a determinada classe (social, religiosa, política) definia o nível de visibilidade e permissão de acesso ao comum.

Se retomarmos a história medieval de Toledo, vemos que a convivência era pacífica sob condições específicas, não sendo uma configuração "natural". Mesmo que a cidade fosse habitada por povos de diferentes religiões, havia uma separação praticada no interior da cidade. No período de domínio muçulmano, cristãos e judeus eram obrigados a pagar impostos por professarem religiões distintas. Estes últimos, por serem responsáveis pela cobrança, eram mal vistos e alvo de constantes perseguições. Na verdade, os próprios judeus não se opunham a essa decisão, pois também não queriam ser "contaminados". Já os moçárabes tinham maior liberdade de trânsito, por falar a língua árabe e ter incorporado alguns de seus costumes. Não viviam concentrados em uma única área da cidade; embora inicialmente não fosse

\footnotetext{
12 Este pensamento vem de Michel de Certeau, que desenvolve uma reflexão sobre as questões advindas dos modos do sujeito de se inserir no mundo, por diferentes práticas, diferenciando "espaço" e "lugar" com base nas apropriações pelos sujeitos. Lugar é "[...] uma configuração instantânea de posições. Implica uma relação de estabilidade". Já espaço é prática do lugar. É o resultado das transformações, ocupações, apropriações e vivências dos sujeitos (CERTEAU, 1998, p. 201).
} 
do agrado muçulmano, estes acabaram se acostumando com a presença cristã por toda parte. A situação se inverte parcialmente quando os cristãos assumem o poder; os muçulmanos diminuem em número e são tolerados, enquanto os judeus pouco a pouco são perseguidos e mortos (até que todos sejam expulsos). Neste contexto, a única maneira de sentir livremente o espaço da cidade era se convertendo à religião do poder dominante. Havia, inclusive, diversos incentivos, como concessão de liberdade para escravos e liberação de impostos.

Toda essa questão político-religiosa influenciou diretamente a produção artística e arquitetônica, em que a convivência parece ter sido mais profícua. Se é possível identificar uma síntese da produção artística das três culturas, esta é percebida na arquitetura:

A conquista cristã de Toledo supôs o contato direto com uma importante cidade islâmica de estrutura plenamente definida, com um amplo repertório de edifícios destacáveis. Ambos elementos - urbanismo e arquitetura - despertaram assombro e admiração na nova população dominante, que ainda não havia conhecido o florescimento de suas cidades e cujas classes privilegiadas costumavam habitar inóspitas e austeras fortalezas situadas no campo (MONZÓN; MATILLA, 2013, p. 35. Tradução nossa). ${ }^{13}$

Passada a fase de entusiasmo e assimilação, a partir do século 13, espaços construídos para um fim e com uma característica formal específica eram adaptados a um novo uso e tinham parte de sua fisionomia alterada. Um exemplo é o apagamento da decoração interior de diversas mesquitas por cristãos, quando estas foram transformadas em igrejas e catedrais. Os elementos formais espalhados pela cidade são basicamente muçulmanos e cristãos; a contribuição judaica deu-se no patrocínio das obras.

A respeito do urbanismo da cidade, uma imagem quase idílica de Toledo foi construída. A cidade era repleta de jardins e hortas, irrigados por múltiplos canais que traziam a água do Tejo, estrutura que foi desenvolvida pelos muçulmanos e aproveitada pelos cristãos. Certamente, é no uso da água que constatamos o que existe de comum para ambas as culturas: a relação de dependência com o rio e a simbologia da água.

A água é o elemento que de fato uniu os três povos, sendo essencial para a proteção e manutenção da vida comum. Além disso, existe um simbolismo atribuído a este elemento, que faz parte dos rituais religiosos de purificação: os muçulmanos se lavam antes de entrar na mesquita, os judeus fazem um banho de imersão (Mikveh) para purificação e os cristãos atribuem ao batismo o mesmo significado. $O$ rio era o único espaço partilhado inteiramente por todas as culturas.

Para Rancière, a partilha do sensível está no domínio da política e da estética, que é mais que uma teoria da arte. É um "modo de articulação entre maneiras de fazer, formas de visibilidade e modos de pensabilidade dessas relações" (RANCIĖRE,

13 "La conquista cristiana de Toledo supuso el contacto directo con una importante ciudad islámica de estructura plenamente definida, con un amplio repertorio de edificios destacables. Ambos elementos - urbanismo y arquitectura - despertaron el asombro y admiración en la nueva población dominante, que aún no había conocido el florecimiento de sus ciudades y cuyas clases privilegiadas solían habitar inhóspitas y austeras fortalezas situadas en el campo." (MONZÓN; MATILLA, 2013, p. 35). 
2005, p. 13). Se no passado a convivência promovia uma partilha desigual, o que Tres Aguas faz é reconfigurar essa partilha do sensível. As vias pelas quais a reconfigura é reativando espaços abandonados, não com o sentido de revitalização de ruínas, mas dando-lhes um status de visibilidade antes inexistente. $O$ conjunto escultórico também exige a caminhada por diversos âmbitos da cidade, reconfigurando a experiência tradicionalmente turística que se tem em Toledo. Iglesias retoma formas visíveis da água para prestar uma homenagem ao Tejo, elemento essencial naquela paisagem; mas principalmente promove o encontro de tempos díspares: presente e passado.

\section{Alguns desdobramentos de Tres Aguas: considerações finais}

O espaço urbano de Toledo permanece sendo partilhado e, apesar de não sabermos o futuro, podemos supor que seguirá assim por tempo indeterminado. Não podemos afirmar com certeza a vida futura desta obra, mas podemos fazer algumas suposições da "vida pós-inauguração". De fato, parece aprazível que um projeto escultórico deste porte, projetado por uma artista consolidada como Cristina Iglesias, tenha sede em Toledo, uma cidade "fora da rota" da arte contemporânea na Espanha. Entretanto, desde sua construção, Tres Aguas foi alvo de inúmeras críticas, nem sempre construtivas ou positivas. Novamente, há uma tensão entre estético e político, localizada na aceitação ou não da obra pela população toledana. Tratando-se de uma obra em espaço público, ocupa um lugar que deve ser partilhado por todos. Mas e quando nem todos querem compartilhar? E quando a obra não atende às expectativas estéticas da população local? É importante lembrar que toda arte pública está sujeita ao debate público; não são apenas obras ou objetos produzidos isoladamente por artistas, mas referem-se a toda uma comunidade (BEARDSLEY,1981, pp. 09-10).

Toda intervenção urbana (aqui compreendida como uma vertente da arte pública) implica uma reflexão sobre tudo que envolve a cidade: seu histórico, a distribuição de seus espaços, sua lógica de funcionamento, o fluxo de pessoas e mercadorias, a arquitetura, a paisagem, o clima, a cultura, etc. (BARJA, 2008, pp. 212-213). Não sabemos se Iglesias considerou todas essas perspectivas em seu projeto; mas sabemos que o resultado não correspondeu às expectativas, ao menos em seus primeiros anos. Às vésperas da inauguração (ocorrida com atraso de três semanas), a população estava bastante incomodada com a alteração na paisagem causada pela presença de máquinas e pelas obras. Tampouco após a inauguração os ânimos se acalmaram. Na verdade, o incômodo referia-se especialmente à obra localizada na Plaza del Ayuntamiento, a "mais pública" de todas.

Comentários sobre o aspecto incompreensível da obra eram frequentes: "isso não é uma fonte, mas um pedaço de rio que eles trouxeram para a praça", "Um rio sujo e sem graça. As fontes têm que fazer coisas, lançar jatos, levantar-se acima do solo, fazer barulhos de salpicos". Também questionava-se a necessidade da intervenção: "Não há quem o entenda, é um centro de lixo que dará muito trabalho aos varredores de ruas", "cuidado para não cair no chão porque você não consegue ver se está distraído", e "uma boa fonte de granito é que deveria ter sido colocada" (PUES 
a mí me gusta, 2014). Por fim, algumas reclamações referiam-se aos altos custos de construção e de manutenção, não se sustentando por muito tempo, já que a execução e manutenção do projeto foi por financiamento privado.

Podemos fazer diversas suposições a respeito dessas críticas, entre as quais citamos: 1- o projeto foi desenvolvido sem considerar a população; 2- a intervenção feita não se integrou totalmente ao espaço eleito; 3 - a obra é repleta de informações e significados que não são partilhados pela população. Quatro anos se passaram e é difícil saber se finalmente as pessoas sentem a obra como a artista a imaginou: "símbolo e metáfora do fluir de pessoas, conhecimentos e diálogos" (MUÑOZ, 2014). Há quem afirme que a relação entre a obra e os toledanos tem melhorado, graças ao passar do tempo e à realização de visitas guiadas que "explicam" a obra. Iglesias também reconhece: "não sou ingênua. É muito difícil fazer uma obra pública e que ela seja aceita imediatamente, ou que seja aceita". (VILLOTA, 2018) Mas é justamente graças a uma suposta ingenuidade que Tres Aguas sobrevive para um futuro:

\begin{abstract}
A fonte é um acúmulo utópico de desejos, a prova física de como Iglesias idealizou nossa cidade. Muito ingênua deve ser ao acreditar que deixaremos livre nossa imaginação durante meia hora enquanto o ciclo da água se completa, em pensar que ninguém olhará impaciente a tela de seu telefone, em imaginar que teremos todo esse tempo para dedicar a nós mesmos, que gozaremos da natureza extenuada do leito de um rio de aço inoxidável patinado de verde, ou que suportaremos melhor as luzes da catedral ao vê-las na lâmina de água escura, ou que transportaremos o rio Tejo a este pedaço preso em paralelepípedos de pedra ou que seremos capazes de manter limpo o centro nevrálgico do turismo de nossa cidade (PUES a mí me gusta, 2014. Tradução nossa).
\end{abstract}

A certeza que se tem é que, provavelmente, Tres Aguas tem um futuro mais duradouro que o nosso.

\title{
Referências bibliográficas
}

BARJA, Wagner. Intervenção/terinvenção: a arte de inventar e intervir diretamente sobre o urbano, suas categorias e o impacto no cotidiano in Revista Ibero-americana de Ciência da Informação (RICl), v. 1, n. 1, p. 213-218, jul./dez. 2008.

BEARDSLEY, John. Art in public places. Washington: Partness Partners for Livable Places, 1981.

CERTEAU, Michel de. A invenção do cotidiano. Petrópolis: Vozes, 1998.

MíGUEZ, Antonio E. Momplet. El Arte Hispanomusulmán. Madrid: Encuentro, 2008. E-book. ISBN Digital: 978-84-9920-507-6

MONZÓN, Olga Pérez; MATILLA, Enrique Rodríguez-Picavea. Toledo y las tres culturas. Madrid: Akal, 2013. 
MUÑOZ, María José. Plan para «explicar» la fuente de Cristina Iglesias a los ciudadanos. $A B C, 27$ mayo 2014. Disponível em: http://www.abc.es/toledo/ciudad/20140521/ abci-plan-para-explicar-fuente-201405212206.html. Acesso em 28.03.2018.

PUES a mí me gusta. ABC, 06 mayo 2014. Disponível em http://www.abc.es/toledo/20140506/abcp-pues-gusta-20140506.html. Acesso em 28.03.2018.

RANCIÈRE, Jacques. Políticas da escrita. Rio de Janeiro: Ed. 34, 1995.

A partilha do Sensível. Rio de Janeiro: Ed. 34, 2005.

SÁNCHEZ, Valle. Cristina Iglesias: «Mucha gente ya ha hecho suyo el proyecto Tres Aguas». ABC, 26 febrero 2017. Disponível em http://www.abc.es/espana/castilla-la-mancha/toledo/abci-cristina-iglesias-mucha-gente-hecho-suyo-proyecto-tres-aguas-201702261912_noticia.html. Acesso em 28.03.2018.

TRES Aguas. A Project for Toledo. Espanha, 2017. Disponível em http://www.cristinaiglesias.com/exposiciones/Tres-Aguas-A-Project-for-Toledo-2014/. Acesso em: 20.03.2017.

VILLOTA, I.G. Toledo siente las "Tres Aguas" de Cristina Iglesias. La Tribuna de Toledo, Toledo, 24 febrero 2018. Disponível em http://www.latribunadetoledo.es/noticia/ ZDAECD9CF-B816-93C4-3D23CFC65055C5E8/Toledo-siente-las-Tres-Aguas-de-Cristina-Iglesias. Acesso em 28.03.2018. 